\title{
The Investigation of Primary School Students' Ability to Identify Quadrilaterals: A Case of Rectangle and Square
}

\author{
Nguyen Phu Loc ${ }^{1}$, Duong Huu Tong ${ }^{2}$, Ngo Thi Be Hai ${ }^{3}$ \\ ${ }^{I}$ School of Education, Can Tho University, Vietnam \\ ${ }^{2}$ School of Education, Can Tho University, Vietnam \\ ${ }^{3}$ Primary School Teacher, Vinh Chau City, Soc Trang Province, Vietnam
}

\begin{abstract}
-ABSTRACT-
In Vietnamese mathematics curricula, primary school students explicitly learn the concept of quadrilaterals such as parallelogram, rhombus, rectangle, square and trapezoid in the Grades 3, 4 and 5. They are presented individually, and there is no comparison between their characteristics. Therefore, the students will be difficult to recognize the relationships among kinds of quadrilaterals. The results of an investigation of 186 primary school students revealed that most of them found it easy to identify squares and rectangles but many of them asserted that "a square is not a rectangle".
\end{abstract}

Keywords: quadrilateral, teaching and learning quadrilaterals, mathematics in primary schools, mathematics education

Date of Submission: 02 March $2017 \quad$ Date of Accepted: 20 March 2017

\section{INTRODUCTION}

Geometry appeared very early in the history of mathematics and it had numerous applications in human life. For this reason, mathematicians as well as educators were deeply concerned about it. Indeed, there were many works on teaching geometry, in particular, a lot of research papers of teaching quadrilaterals were made by authors around the world.

Türnüklü and Funda [1] had a specific investigation of ways to define and classify the quadrilaterals gone by 36 prospective primary mathematics teachers in an educational faculty in Turkey. They were asked to make their personal definitions for quadrilaterals. It was observed that their perceptions were not accurate. For example, they had difficulties expressing the differences between rhombus and square because they were influenced by their images in rhombus. Also, they used partition classification with side and angle properties when classifying quadrilaterals, while they were expected to make a hierarchical classification more commonly and set up family relations rightly.

A survey of 28 seventh grade students in Cyprus to find out their difficulties in answering geometry questions of measures was carefully conducted by Ayşen Özerem [2]. The author used the descriptive methodology and student interview in the study to analyze and interpret the results. It was revealed that they had some misconceptions, lacked background knowledge and made reasoning and basic operation errors. At the end of the paper, the researcher made some suggestions to help students to study geometry effectively such as: developing the thinking and reasoning abilities of students, improving their perceptions of recognizing the shapes by rotating the objects mentally and using visual aids.

Panaoura and Gagatsis [3] investigated the abilities of the geometrical reasoning of primary and secondary school students in France through two tasks: the strategies they used and the errors made in their answers. The survey consisted of 1000 students who had to solve three given geometrical tasks involved two-dimensional figures. The results shed light to students' difficulties and phenomena related to the transition from the geometry of observation to the geometry of deduction. Accordingly, students' strategies revealed that the didactical contract was established among teachers and students concerning geometry learning in primary school education, but it did not appear in secondary schools. Therefore, the authors called this phenomenon "inconsistency of the didactical contract" among the two education levels.

Three Turkish authors, Biber, Tuna and Korkmaz [4], tested 30 eighth grade students to find out their errors and misconceptions on the topic of angles. On the basis of this study, students had to answer 4 open-ended questions. The findings indicated that the mistakes and the misperceptions of students were determined. The principal reason for this was that students tended to pay attention to the physical appearances of geometric figures instead of the geometric properties of figures. In addition, students could find out some properties of figures, but they did not succeed in connecting them with other knowledge to adapt to new situations. Furthermore, the concept of 
parallelism on the subject of angles was not mastered by most students. In the conclusion of the paper, the researchers emphasized teachers' important role in removing the misconceptions of students.

Ilham Rizkianto, Zulkardi and Darmawijaya [5] organized a sequence of instructional activities along with computer manipulative to help 37 Indonesian third graders to form geometrical properties of square, rectangle, and triangle. These activities were composed of 4 steps: preparation phase, preliminary teaching experiment, teaching experiment and post-test. The results of the survey brought students effective activities to develop understanding the concepts of shapes due to computer manipulative. For instance, they could find out the reasons why the opposite sides of rectangle and square have to be in the same length, then establish the relation between rectangle and square. Additionally, the second computer manipulative helped them to construct the properties of triangles. The last activity supported students in seeking another geometrical property of rectangle. Thanks to this property, the formula to find perimeter of a rectangle was formed.

A detailed test of misconceptions about parallelograms was carried out by Katarína Žilková [6]. A research sample concluded 159 pre-service teachers in Slovakia who had to reply 8 questions about the basis properties of parallelograms. The aim of the authors was to know their conception and misconceptions of squares, rhombuses, rectangles and parallelograms. Some main results were that most future pre-service teachers failed to identify geometric shapes because of their changed orientation, and they also did not comprehend very well the properties of a convex quadrilateral. Therefore, some activities were recommended to correct mental understanding of geometrical concepts and objects in these pre-service teachers.

To examine pre-service teachers' subject matter knowledge and pedagogical content knowledge, Berna Cantürk Günhan [7] asked them to reply open-ended questions about quadrilaterals. In this case study, their geometrical thinking levels were divided into five levels. The result was that pre-service teachers whose geometrical thinking levels were low and poor, confused the relationship among quadrilaterals. In fact, their subject matter knowledge in interpreting and making sense of the quadrilaterals was not sufficiently deep. For the pedagogical content knowledge, they interpreted the relations between quadrilaterals wrongly. Hence, it is suggested that pre-service teachers need to improve subject matter knowledge and pedagogical content knowledge before they begin their careers. More specifically, faculty of school should add some courses to the training curriculum to support them in developing these knowledge, and the teaching environments should be created to encourage them to practice in the lessons.

In the particular study of Elif Nur Akkaş and Elif Türnüklü [8], there were in 30 mathematics teachers in 12 different schools in Turkey and they had to reply questions about the topic of quadrilaterals such as identifying, understanding and drawing special quadrilaterals, indicating their diagonals along with interior and exterior angles, measuring, setting up area relations and solving problems. The teachers' responses were about their student knowledge which was composed of connecting prior knowledge to new knowledge, mistakes made about the topic, difficulties of understanding regarding the topic). The interviews revealed that teachers took into consideration their students' previous knowledge and new knowledge and they pointed out the mistakes and difficulties which their students had when learning quadrilaterals. To conclude, the author believed that it would be helpful to do classroom research with middle school teachers to find out more their students' knowledge regarding quadrilaterals.

Teaching mathematics in Vietnamese primary schools includes topics: arithmetic, quantity and quantity measurements, statistics, geometry and word problems. In particular, the geometry is taught very early, even the students learn geometrical shapes in kindergarten schools. Two main contents emphasized when studying these shapes are their properties and ways to find circumference and area of these shapes. Typically, the properties are introduced first, then to the circumference and area of shapes. Also, squares and rectangles are studied in Mathematics 3 [9], while parallelograms and rhombuses are taught in grade 4 [10]. Finally, trapezoids are presented in the $5^{\text {th }}$ grade mathematics textbook [11]. However, our research only focuses on the properties of shapes, not the perimeter or area of shapes.

As discussed in the previous section, some authors studied the students' understanding of the properties as well as their mistakes while learning geometry. Therefore, the problem we are concerned about is similar to them, but the subject of our study is primary school students in Vietnam. In reality, the geometrical shapes are presented in textbooks with a fixed direction, i.e. they have at least a side parallel to the edge of the paper. In a normal way, teachers adhere to this when they introduce the shapes to students. Because of this, students can have misconceptions about shapes accidentally.

In addition, we are also interested in students' ability of identifying shapes. Through our classroom observation, very few exercises of identifying shapes by analyzing and synthesizing are raised by teachers. For this reason, it can lead to the restriction of students in shape identification.

Besides, textbooks rarely present a comparison of similarities and differences between the shapes. As a consequence, teachers also do not introduce relationship between shapes to students. Sometimes, this results in inaccurate knowledge of students. For instance, it is not accepted for them to say "squares are rectangles". 
The above review allows us to formulate two research questions:

1. Are students able to identify quadrilaterals correctly when their orientation and color are changed?

2. Do students succeed in identifying shapes in situations requiring abilities of analyzing and synthesizing shapes?

The above research questions are restated into the following research hypotheses:

Hypothesis 1: In many cases, if the teachers change the unessential signals of a quadrilateral and retain their essential signals, students will not realize the quadrilaterals.

Hypothesis 2: In the classroom, students are familiar with how to identify a rectangle with a long side and a short side, therefore, they will say that a square is not a rectangle.

Hypothesis 3: Students' abilities of identifying quadrilaterals by analyzing and synthesizing are limited.

Our study is aiming at verifying the above hypotheses.

\section{Instrument and procedure}

\section{METHODOLOGY}

Four questions as below was to used to measure students' ability to identify a square (or a rectangle); students' task is to fill in the blank with $\mathrm{T}$ (True) or $\mathrm{F}$ (Fasle) in 15 minutes.

Question 1. (to verify the hypothesis 1)

Which of the following shapes is a square?

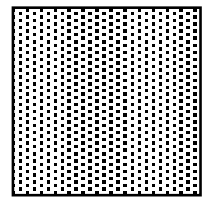

Shape 1

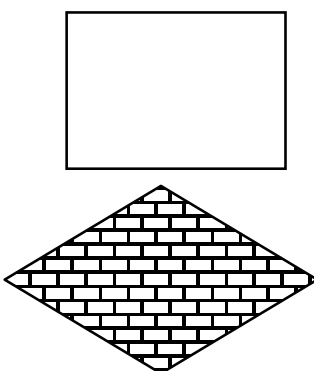

Shape 2

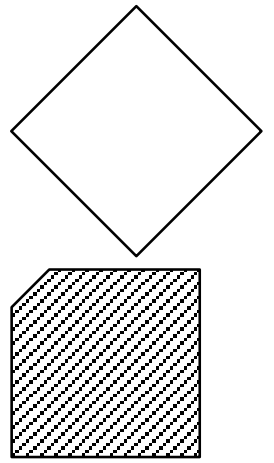

Shape 3

Shape 4

Question 2. (to verify the hypothesis 1)

Which of the following shapes is a rectangle?

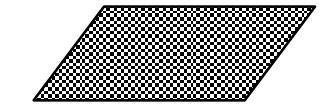

Shape 1

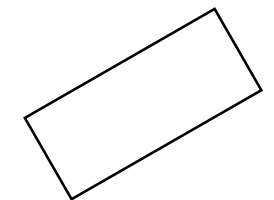

Shape 2

Shape 5

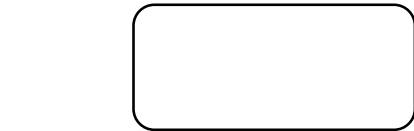

Shape 3 


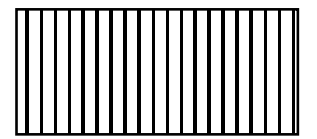

Shape 4

Question 3. (to verify the hypothesis 2)

a. Rectangles and squares are the same shape because both of them have four right angles.

b. A square is a rectangle.

Question 4. (to verify the hypothesis 3)

In the shape below, how many rectangles are there?

a. 4 rectangles .

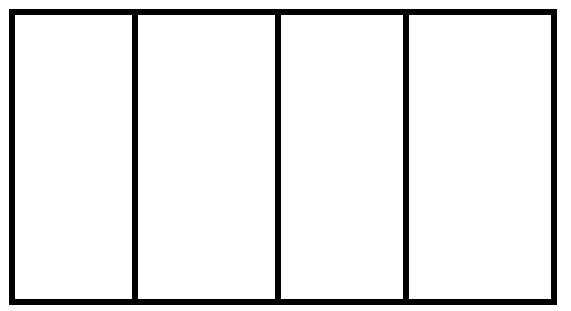

b. 7 rectangles .

c. 10 rectangles

\section{Participants}

There were two grades 3, two grades 4 and four grades 5 in Primary School "Phước Vĩnh 6", Vinh Chau City, Soc Trang province. (see Table 1)

Table 1. The students from classes of Primary School "Phước Vĩnh 6".

\begin{tabular}{|l|l|l|l|l|l|l|l|l|l|}
\hline Class & $3 \mathrm{~A} 1$ & $3 \mathrm{~A} 2$ & $4 \mathrm{~A} 1$ & $4 \mathrm{~A} 2$ & $5 \mathrm{~A} 1$ & $5 \mathrm{~A} 2$ & $5 \mathrm{~A} 3$ & $5 \mathrm{~A} 4$ & Total \\
\hline The number of students & 23 & 19 & 41 & 20 & 21 & 20 & 21 & 21 & 186 \\
\hline
\end{tabular}

The sum of students in eight grades was 186. At the time of testing, they have completed the contents of the quadrilaterals. Time: from March, 2016 to May, 2016.

Pre-analysis of 4 questions

Question 1. (to verify the hypothesis 1)

We want to check if students have realized the square when its unessential signals are changed or not. It is clear that the concept of a square is formed in Grade 3, in particular, the exercises of recognizing squares are mostly placed in the square grid and virtually have unchanged colors. Consequently, that the square is not set in grid square with changed color, or its direction is different from the normal squares in textbooks is not easy for students to identify it.

Shape 1: we propose a shape which is not very familiar to students because of the change of its background.

Shape 2: This shape is a rectangle having the same characteristics as a square such as four right angles, but four unequal sides.

Shape 3: Clearly, this shape is a rhombus having the same characteristics as a square such as four equal sides, but four unequal angles.

Shape 4: This square is very easy for students to identify since they can use a set-square and a centimeter ruler to measure the angles and the length of the sides.

Shape 5: The given shape is not a quadrilateral, whereas a square must be a quadrilateral.

(see Table 1.1)

Table 1.1. The correct answers to the question 1

\begin{tabular}{|l|l|l|l|l|l|}
\hline Shape & 1 & 2 & 3 & 4 & 5 \\
\hline Correct answer & T & F & F & T & F \\
\hline
\end{tabular}

Some possibilities:

Possibility 1: Students have five right answers. They correctly identify squares due to their essential signals. 
Possibility 2: Students have four right answers, except for Shape 4. In this case, they do not realize the square because of its changed direction compared to the normal squares in textbooks.

Possibility 3: Students find that all of the given shapes are not squares. Through this fact, they do not identify squares as their unessential signals are changed.

Question 2. (to verify the hypothesis 1)

Similarly, we want to check if students have realized a rectangle when its unessential signals are changed or not. In these shapes, we change rectangles' colors as well as their direction which differ from that of rectangles in textbooks.

Shape 1: In the given parallelogram, there are two long equal sides and two short equal sides, but the four angles are not right.

Shape 2: To identify this shape to be a rectangle, students can use a set-square to check four right angles and a centimeter ruler to measure the length of four sides.

Shape 3: Easily, students find that four angles of the shape are not right.

Shape 4: When eliminating the unessential signals, students can identify the rectangle with 4 right angles, 2 long equal sides and 2 short equal sides.

(see Table 2.1)

Table 2.1. The correct answers to the question 2

\begin{tabular}{|l|l|l|l|l|}
\hline Shape & 1 & 2 & 3 & 4 \\
\hline Correct answer & F & T & F & T \\
\hline
\end{tabular}

Some possibilities:

Possibility 1: Students have four right answers. Basing on the features of the rectangle as well as the use of devices to measure the length of sides and angles, students can identify the rectangle rightly.

Possibility 2: Students find that all of the given shapes are not rectangles. Therefore, they do not identify rectangles as their unessential signals are changed.

Possibility 3: All of students' answers are Đ because they only are concerned about the length of sides and ignore the equality of four right angles.

Question 3. (to verify the hypothesis 2)

We want to check students' perception of the relation between rectangles and squares. In reality, textbooks do not mention the similarities and differences between square and rectangle. Are students able to compare the two concepts of square and rectangle? They may misconceive that a square is not a rectangle. Maybe, some good students realize that a square is also a special case of a rectangle when its length is equal to its width. The purposes of items are as below:

Item a: We offer a comparison of angles of the rectangle and square. Students easily find that both the rectangle and square have the same four right angles but their shapes are not similar.

Item b: In case, if a rectangle has four equal sides, it is a square. Nonetheless, this may be not realized by most students. (see Table 3.1)

Table 3.1. The correct answers to the question 3

\begin{tabular}{|l|l|l|}
\hline Items & a & b \\
\hline Correct answer & F & T \\
\hline
\end{tabular}

Two possibilities may occur:

Possibility 1: Students give two correct answers. Students are aware of the relation between the rectangle and square. The hypothesis $\mathrm{H} 2$ will be rejected.

Possibility 2: Students give two wrong answers, and the hypothesis 2 will be asserted.

Question 4. (to verify the hypothesis 3)

Normally, a lot of identification exercises are provided on textbooks in grades 1 and 2, but the identification exercises by analyzing and synthesizing are rare in mathematical textbooks in grades 3,4 and 5. Therefore, we want to test the ability of students to recognize shapes by analyzing and synthesizing. In textbooks, there are not any rules of solving for these exercises. If not guided through these strange exercises by their teachers, students will easily mistake. Intuitively, students will recognize the shapes as required, but they often overlook quickly without using analysis and synthesis. 
Table 4.1. presented the correct answers to the question 4

Table 4.1. The correct answers to the question 4

\begin{tabular}{|l|l|l|l|}
\hline Items & a & b & c \\
\hline Correct answer & F & F & T \\
\hline
\end{tabular}

Predicting some students' answers:

Strategy 1: 4 rectangles.

Students could quickly count 4 rectangles in the given shape. At this point, they stop and conclude about the number of rectangles.

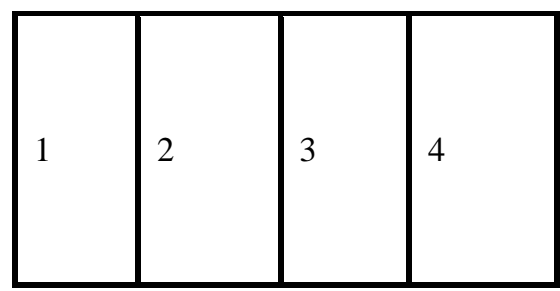

Strategy 2: 7 rectangles.

Students can number rectangles as below:

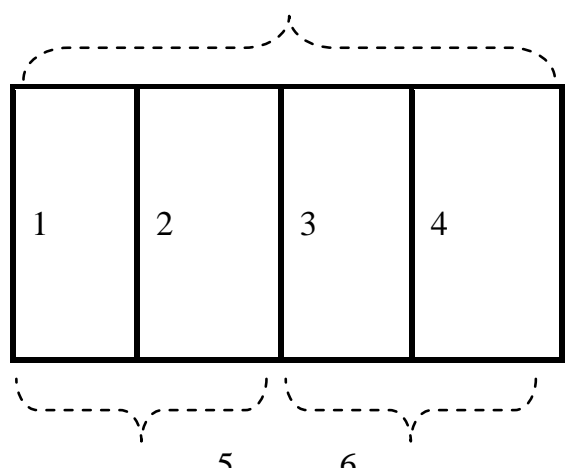

Strategy 3: a correct answer with 10 rectangles.

Students take an edge as common edge, then turn the others to merge and count. They proceed to turn each side and remove duplicate cases.

III. RESULTS AND DISCUSSION

Table 1.2 The answers of students to Question 1

\begin{tabular}{|l|l|l|}
\hline Shapes & Answers & $\%$ of students \\
\hline \multirow{2}{*}{ Shape 1} & T (correct) & $173 / 186(93 \%)$ \\
\cline { 2 - 3 } & F (incorrect) & $13 / 186(7 \%)$ \\
\hline \multirow{2}{*}{ Shape 2 } & $\mathrm{T}$ & $182 / 186(98 \%)$ \\
\cline { 2 - 3 } & $\mathrm{F}$ & $4 / 186(2 \%)$ \\
\hline \multirow{2}{*}{ Shape 3 } & $\mathrm{T}$ & $179 / 186(96 \%)$ \\
\cline { 2 - 3 } & $\mathrm{F}$ & $7 / 186(4 \%)$ \\
\hline \multirow{2}{*}{ Shape 4 } & $\mathrm{T}$ & $96 / 186(52 \%)$ \\
\cline { 2 - 3 } & $\mathrm{F}$ & $90 / 186(48 \%)$ \\
\hline \multirow{2}{*}{ Shape 5 } & $\mathrm{T}$ & $173 / 186(93 \%)$ \\
\cline { 2 - 3 } & $\mathrm{F}$ & $13 / 186(7 \%)$ \\
\hline
\end{tabular}

From Table 1.2, it was evident that the number of students having exact answers was very high. More specifically, in the question 1, the percentages of students identifying squares rightly were $93 \%$ (shape 1) and $52 \%$ (shape 4). The percentage of students with correct answers in shape 1 was higher than that of students with right answers in shape 4 because the shape 1 was very familiar to students while the shape 4 was pretty strange to them. Indeed, its changed direction made it difficult for $48 \%$ of students. The percentages of students identifying that shapes 2, 3, and 5 are squares were very low (shape $2-2 \%$, shape $3-4 \%$ and shape $5-7 \%$ ). It means that almost all participants mastered the knowledge about squares.

Table 2.2 The answers of students to Question 2

\begin{tabular}{|l|l|l|}
\hline Shapes & Answers & \% of students \\
\hline \multirow{2}{*}{ Shape 1} & $\mathrm{~T}$ & $176 / 186(95 \%)$ \\
\cline { 2 - 3 } & $\mathrm{F}$ & $10 / 186(5 \%)$ \\
\hline
\end{tabular}




\begin{tabular}{|l|l|l|}
\hline \multirow{2}{*}{ Shape 2} & T & $138 / 186(74 \%)$ \\
\cline { 2 - 3 } & F & $48 / 186(26 \%)$ \\
\hline \multirow{2}{*}{ Shape 3} & T & $133 / 186(72 \%)$ \\
\cline { 2 - 3 } & F & $158 / 186(85 \%)$ \\
\hline \multirow{2}{*}{ Shape 4} & T & $28 / 186(15 \%)$ \\
\cline { 2 - 3 } & F & $90 / 186(48 \%)$ \\
\hline
\end{tabular}

Question 2 was also surveyed with 186 students whose percentages in shapes 2 and 4 were $74 \%$ and $85 \%$, while a few student thought that shapes 1 and 3 were rectangles (in turn 5\% and 28\%) (see Table 2.2)

Table 3.2. The answers of students to Question 3

\begin{tabular}{|l|l|l|}
\hline Items & Answers & \% of students \\
\hline \multirow{2}{*}{ Item a } & $\mathrm{T}$ & $12 / 186(6 \%)$ \\
\cline { 2 - 3 } & $\mathrm{F}$ & $174 / 186(94 \%)$ \\
\hline \multirow{2}{*}{ Item b } & $\mathrm{T}$ & $10 / 186(5 \%)$ \\
\cline { 2 - 3 } & $\mathrm{F}$ & $176 / 186(95 \%)$ \\
\hline
\end{tabular}

The Table 3.2 indicated that the majority of students chose (F) in both items a and b (94\% and 95\%). It means that for students, the rectangle and the square are not similar. It could be that students were not clarified about this when they studied the concepts of square and rectangle. Hence, it was certain to affirm the hypothesis H2.

Table 4.2. The answers of students to Question 4

\begin{tabular}{|l|l|l|}
\hline Items & Answers & \% of students \\
\hline \multirow{3}{*}{ Strategies } & S1 & $87 / 186(47 \%)$ \\
\cline { 2 - 3 } & S2 & $34 / 186(18 \%)$ \\
\cline { 2 - 3 } & S3 & $50 / 186(27 \%)$ \\
\hline
\end{tabular}

In question 4, S1 and S2 were strategies leading to wrong answers. The Table 4.2 showed that the percentages of these two strategies were $47 \%$ and $18 \%$, whereas the correct answer was related to S3, (accounted for 27\%). There was no denying the fact that the number of students having the wrong answer was higher than that of students having the right answer. The reason for this was due to their particularly limited capacity of analyzing and synthesizing shapes. Correspondingly, the hypothesis $\mathrm{H} 3$ was still asserted.

\section{CONCLUSION}

From the results of the study, the hypothesis $\mathrm{H} 1$ was rejected because of the high percentages of students giving correct answers to the questions, and the remaining two hypotheses were certainly asserted. Students' recognition on the overall shapes was pretty good; however, the recognition of shapes by analyzing and synthesizing was quite restricted. Besides, that the comparison between the learned concepts and the new concepts in the learning process was less concerned about leads students to be unaware of the relationship between the quadrilaterals together. If the proposed hypotheses are cared about by primary school teachers, educators, and the authors of textbooks and they use the appropriate pedagogical measures, the quality of teaching contents of quadrilaterals will be improved.

\section{REFERENCES}

[1]. Türnüklü, E. \& Alayl, F., G. (2013). Investigation of Prospective Primary Mathematics Teachers' Perceptions and Images for Quadrilaterals, Educational Sciences: Theory \& Practice, 13(2), 1225-1232.

[2]. Özerem, A. (2012). Misconceptions In Geometry And Suggested Solutions For Seventh Grade Students, International Journal of New Trends in Arts, Sports \& Science Education, 1(4), 23-35.

[3]. Panaoura, G. \& Gagatsis, A. (2009). The geometrical reasoning of primary and secondary school students, Proceedings of CERME 6, January 28th-February 1st 2009, 746-755.

[4]. Biber, C., Tuna, A. \& Korkmaz, S. (2013). The mistakes and the misconceptions of the eighth grade students on the subject of angles, European Journal of Science and Mathematics Education, 1 (2), 50-59.

[5]. Rizkianto, I., Zulkardi \& Darmawijaya (2013). Constructing Geometric Properties Of Rectangle, Square, And Triangle In The Third Grade Of Indonesian Primary Schools, IndoMS-JME, 4(2), 160-171.

[6]. Žilková, K. (2014). Parallelogram Conceptions and Misconceptions of Students Who Study to Become Teachers in Pre-Primary and Primary Education, Indian Journal of Applied Research, 4(7), 128-130.

[7]. Günhan, B. C. (2014). An Investigation of Pre-Service Elementary School Teachers' Knowledge Concerning Quadrilaterals, Çukurova Üniversitesi Eğitim Fakültesi Dergisi, 43(2), 2014, 137-154.

[8]. Akkaş, E. N. \& Türnüklü, E. (2015). Middle School Mathematics Teachers' Pedagogical Content Knowledge Regarding Student Knowledge about Quadrilaterals, Elementary Education Online, 14(2), 744-756.

[9]. Hoan, Đ. Đ. (editor). (2007). Mathematics 3 (Toán 3), Hanoi: Publishing house Giáo dục. (in Vietnamese).

[10]. Hoan, Đ. Đ. (editor). (2007). Mathematics 4 (Toán 4), Hanoi: Publishing house Giáo dục. (in Vietnamese)

[11]. Hoan, Đ. Đ.(editor). (2007). Mathematics 5 (Toán 5), Hanoi: Publishing house Giáo dục. (in Vietnamese). 